\title{
EFFECT OF PRE-CUT ASPHALT FRACTURE PLANES ON HIGHWAY GUARDRAIL PERFORMANCE
}

\author{
S.H. LEE, E. BAKHTIARY, L.K. STEWART, D. SCOTT \& D. WHITE \\ School of Civil and Environmental Engineering, Georgia Institute of Technology, USA.
}

\begin{abstract}
The preferred procedure for steel guardrails in the state of Georgia, USA for vehicle impact employs a post-installation machine to drive the posts through a layer of asphalt placed to retard vegetation growth around the system. However, in order to avoid undesirable restraint at the ground line, the AASHTO Roadside Design Guide recommends incorporating leave-outs. Using a leave-out in vegetation barriers is seen as less desirable because of issues including significantly higher expected costs, variability in the placement and spacing of posts, and the need for variable construction scheduling. In lieu of leaveouts, predetermined fracture planes, or "pre-cuts" were installed in the asphalt and evaluated in terms of ground restraint. An experimental program was carried out on an outdoor test site. Posts were installed in pre-cut asphalt and subjected to static loading to provide a better understanding of the behavior of a post restrained with an asphalt layer at the ground line. In parallel with the experimental program, a three dimensional finite element model was developed for a guardrail post installed through an asphalt layer. The model was refined using the experimental results from the test program as well as material testing. Results from the experimental program and finite element analyses indicate that certain precutting configurations lead to significantly less ground restraint as desired.
\end{abstract}

Keywords: asphalt, guardrail, pre-cuts, vehicle impact.

\section{INTRODUCTION}

\subsection{Standard practice}

The most widely used guardrail post in the state of Georgia is the Type D wide-flange steel post. According to the Georgia Department of Transportation (GDOT) Construction Specification 641.3.05 [1], asphalt mow strip installation around the post is optional, but recommended for roadside vegetation control. In Georgia, the mow strip typically consists of two layers of asphalt: a top layer of $3.8 \mathrm{~cm}$ (1.5 in) thickness and a $5 \mathrm{~cm}$ ( 2 in) thick bottom layer [2].

The GDOT Construction Specification allows multiple methods for guardrail post installation in areas with asphalt mow strips. The preferred method employs a hydraulic post-installation machine to drive the posts through the asphalt mow strip and into the soil base. This installation method is considered by GDOT to be the most economical and allows better quality control during the construction process [3]. Using a leave-out, shown in Fig. 1, for posts in vegetation barriers is seen as less desirable because of issues including significantly higher expected costs for new construction and repairs, variability in the placement and spacing of posts, and the need for multi-phase construction scheduling. 


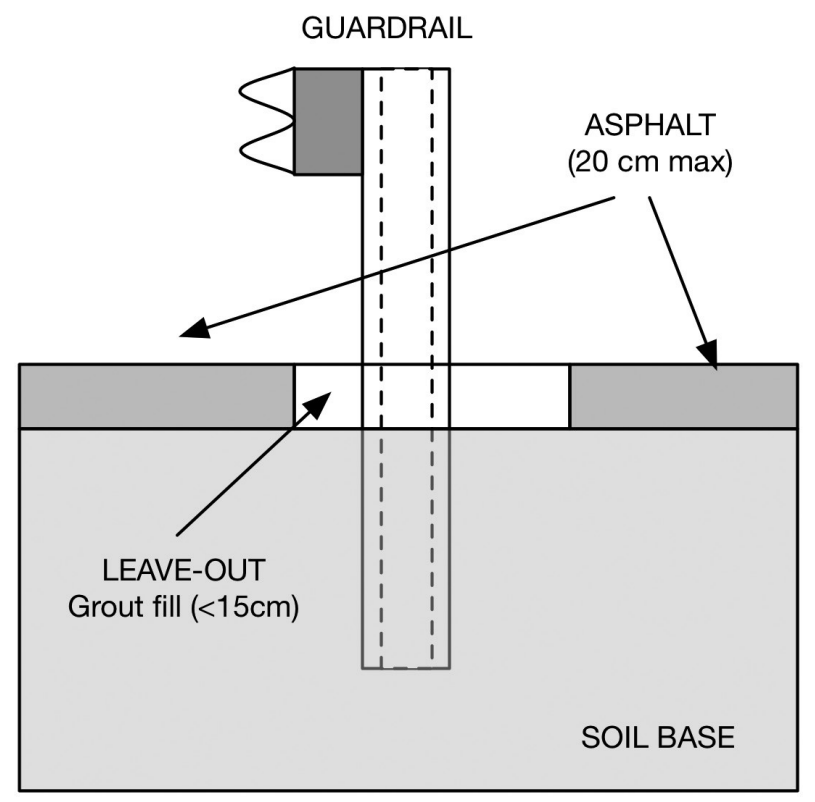

Figure 1: Typical vehicle guardrail installation with leave-out.

\subsection{Motivation}

In lieu of leave-outs, pre-cutting the asphalt was investigated as a means to reduce the ground restraint. This investigation was motivated from initial experimental results in which rupture was observed to be the primary mechanism of the asphalt failure under static loading. As the rupture extends in the asphalt, the strength of the asphalt layer decreases up to the point that one section of the asphalt detaches from the rest of the mow strip. After this occurs the asphalt has a negligible impact on the system and the soil is the only source of ground restraint. Therefore, one potentially effective way to decrease mow strip restraint would be to introduce predetermined fracture planes (referred to as "pre-cuts") in the asphalt layer. A controlled rupture along a pre-determined fracture plane in the asphalt avoids uncontrolled crack propagation in a large area and potentially reduces expected maintenance costs.

\subsection{Review of prior work}

A large volume of work exists in the literature regarding the testing of guardrail posts and systems. Summaries of representative work are presented below.

A synthesis report by Ray and McGinnis [4] provides a broad summary of crash testing for various barrier types. Articles by Reid [5] and Atahan [6] provide detailed reviews of finite element simulations of vehicle barrier impacts. Atahan [7] conducted an explicit nonlinear finite element simulation of a strong-post W-beam guardrail system. The results of a previously conducted full-scale crash test of a failed guardrail system were used in the study. Before the next full-scale crash test, numerical simulations of the failed system were 
used to identify the cause of the failure, and to propose possible improvements to the system. Borovinsek et al. [8] and Ren and Vesenjak [9] used computational crash simulations for the early evaluation of different guardrail setups and determination of the best barrier design for high and low containment levels. Plaxico et al. [10] performed a full-scale crash test on a W-beam guardrail system and also performed a nonlinear finite element analysis using LS-DYNA [11]. Further, Plaxico et al. [12] performed finite element modeling of guardrail timber posts and the post soil interaction. In this study, the post soil interaction was modeled using the subgrade reaction approach, which involves an array of nonlinear springs attached along the length of the post below grade. Tabiei and $\mathrm{Wu}[13,14]$ performed a finite element simulation of a strong W-beam guardrail post to be used in full-scale crash test simulations using an Eulerian formulation to model the soil media as part of the overall system.

Research performed by the Texas Transportation Institute to investigate the impact of mowstrips on the performance of guardrail systems [15] formed the basis for the adoption of the guardrail post installation detail incorporating grout leave outs into the Roadside Design Guide. The researchers examined the performance of guardrail/mowstrip systems using experimental testing and numerical simulation. Mow strip dimensions and materials were considered in addition to the presence of "leave-out" sections around the posts. Seventeen configurations of wood and steel guardrail posts embedded in various mow strip systems and confinement conditions were subjected to dynamic impact testing with a bogie vehicle. The dynamic impact tests were numerically simulated, and full-scale mow strip system models were assembled using the subcomponent models. Based on predictive numerical simulations, a concrete mow strip with grout-filled leave outs was selected for full-scale crash testing in accordance with NCHRP 350 criteria [16]. Crash tests of a steel post guardrail system and wood post guardrail system encased in the selected mow strip configuration were deemed successful.

\section{EXPERIMENTAL PROGRAM}

\subsection{Test setup}

The experimental setup was constructed in accordance with American Association of State Highway and Transportation Officials (AASHTO) Manual for Assessing Safety Hardware (MASH) criteria [17]. The aggregate base material was standardized and compacted to exceed $95 \%$ of the maximum dry density of soil for each test configuration. In each test, a hot mixed asphalt layer of PG 76-22 binder and $19 \mathrm{~mm}$ aggregate size was installed to a specified thickness. Approximately one week after the asphalt installation, W150 $\times 13$ steel guardrail posts were driven $1,000 \mathrm{~mm}$ through the asphalt layer and into the ground with a hydraulic post driver.

A schematic of the experiment is given in Fig. 2. A hydraulic cylinder was used to apply a lateral load on the guardrail post at a rate of $0.5 \mathrm{~mm} / \mathrm{s}$. A reaction block prevented the lateral movement, forcing the post to displace toward the block as the cylinder retracts. A load cell was connected from the hydraulic cylinder to the post via a bracket system. Threaded rods were attached on both sides of the load cell to prevent bending and torsion along the load axis. Two string potentiometers were mounted on a reference pole to measure lateral displacement at the load point ( $625 \mathrm{~mm}$ above ground level) and at the ground level. To minimize the discrepancy between the inclined distance and actual horizontal distance, a reference pole was located with a stand-off distance of approximately $1.8 \mathrm{~m}$ from the post. 


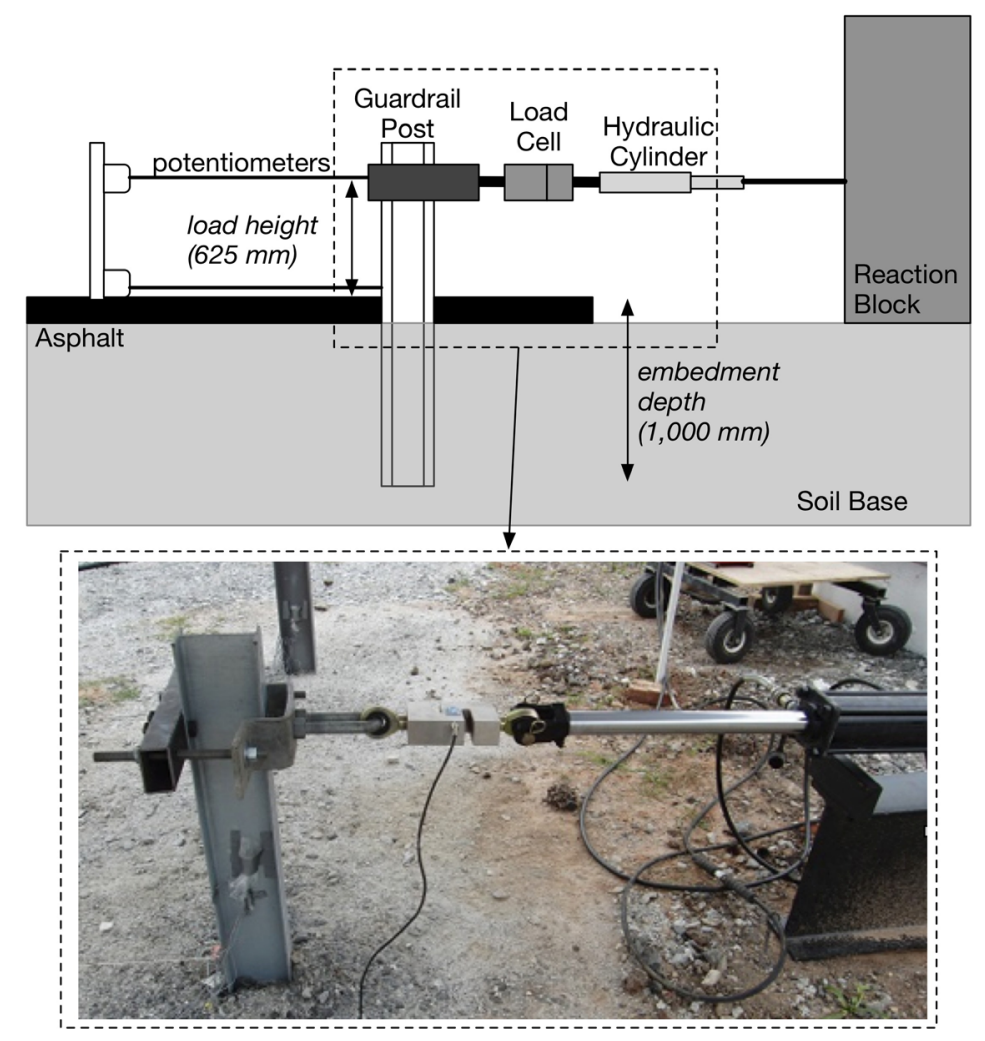

Figure 2: Experimental setup.

A computer-controlled data acquisition system was used to measure and record the laterally applied load and displacements.

\subsection{Test specimen}

Two experiments on posts with pre-cut mow strips were conducted as well as a variety of tests with no pre-cuts. The orientation of the cuts placed in the asphalt layer was selected based on observations of the asphalt failure mechanism in tests performed in the previous experiments as well as finite element analysis results that will be discussed in the following section. A schematic of the two pre-cut patterns employed in the experimental program is shown in Fig. 3. The parallel pre-cut involved two vertical cuts at least $15 \mathrm{~cm}$ from the post on each side. The diagonal pre-cut involved two 45 degree angle cuts starting at $15 \mathrm{~cm}$ from the post on each side. The asphalt was $5 \mathrm{~cm}$ and $9 \mathrm{~cm}$ thick for the parallel and diagonal cuts, respectively, and the post was $60 \mathrm{~cm}$ from the rear of the asphalt.

\subsection{Results}

Results from the experimental program for both cases without pre-cuts and cases with precuts are discussed in the following two sections. 


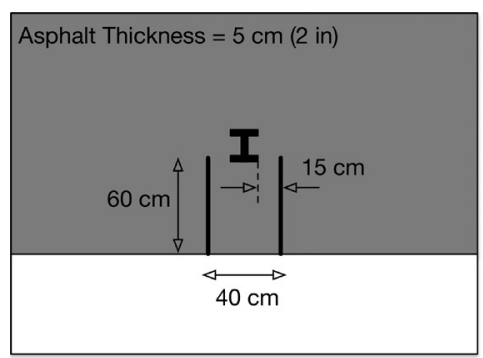

(a)

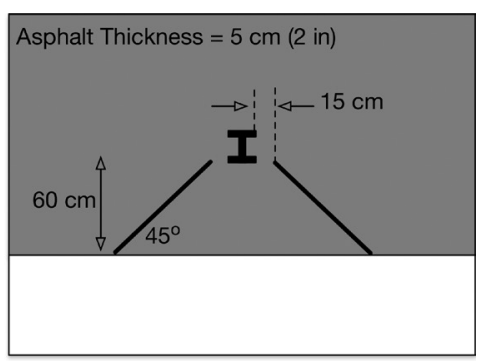

(b)

Figure 3: Pre-cut mow strip patterns tested: (a) parallel, (b) diagonal.

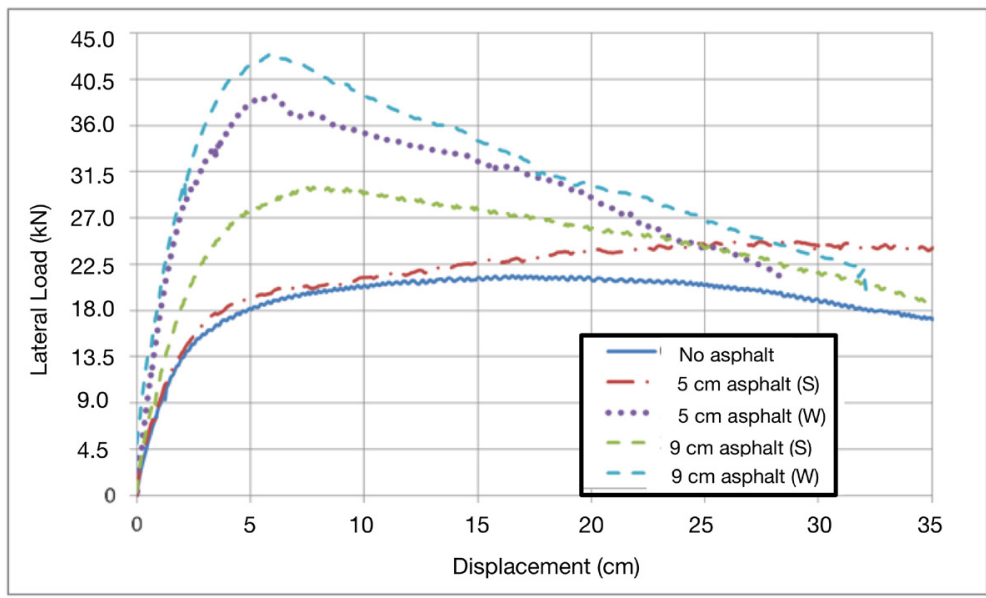

Figure 4: Load-displacement curves from tests without pre-cuts.

\subsubsection{No pre-cut experiments}

Results from the asphalt experiments without pre-cuts are given in detail in Scott et al. [18]. Representative load-displacement curves for five experiments, including one test with no asphalt is shown in Fig. 4. Tests performed on the posts demonstrated the impact of service conditions. The curves shown in Fig. 4 indicate that tests performed in summer conditions (denoted with an $\mathrm{S}$ ) resulted in less restraint provided by the asphalt layer than those tested in winter conditions (denoted with a W). As expected, for a given service condition mow strips of greater thickness provided a higher level of restraint on the post which is evidenced by the high-recorded peak force.

\subsubsection{Parallel pre-cut experiment}

Figure 5 gives before and after conditions for a post tested $(5 \mathrm{~cm} \mathrm{~W})$ with parallel pre-installed cuts in the mow strip behind the post. The cuts introduced in the mow strip prior to testing resulted in a controlled and easily predicted asphalt failure mechanism as shown. In addition, the force-displacement behavior of the post is given in Fig. 6. These values were significantly lower than those from the previous tests using the preferred installation method. The peak load was measured to be $30.7 \mathrm{kN}(6,912 \mathrm{lb})$ with a corresponding displacement of $8.2 \mathrm{~cm}$ (3.22 in). 

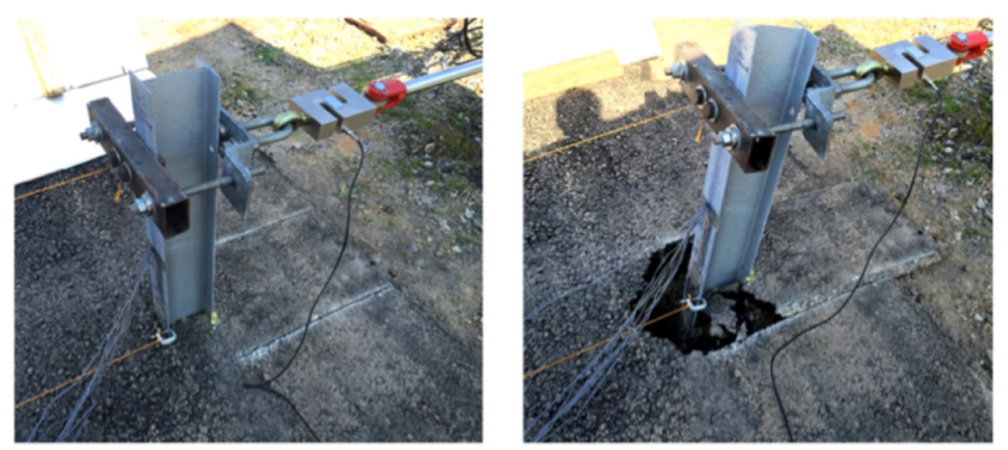

Figure 5: Parallel pre-cut experiment.

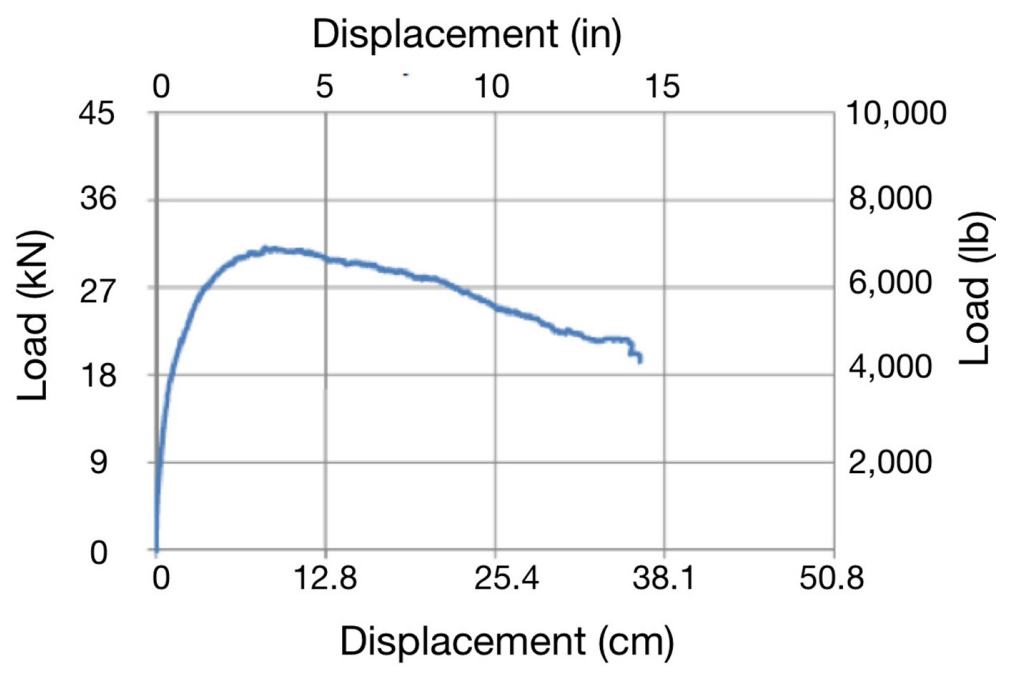

Figure 6: Load-displacement curve from parallel pre-cut experiment.

\subsubsection{Diagonal pre-cut experiment}

A diagonal pre-cut experiment was conducted and Fig. 7 gives before and after conditions for the post tested $(9 \mathrm{~cm} \mathrm{~W})$. The force-displacement behavior of the post is given in Fig. 8 . These values were significantly lower than those from the previous tests using the preferred installation method. The peak load was measured to be $33.7 \mathrm{kN}(7,577 \mathrm{lb})$ with a corresponding displacement of $6.35 \mathrm{~cm}$ (2.5 in).

\section{COMPUTATIONAL MODEL}

The following section includes a description of the finite element model created as part of this research effort as well as comparisons to the experiments discussed in Section 2.

\subsection{LS-DYNA model}

An explicit finite element model was created using LS-DYNA V971 R8.0.0. In the model, the soil domain was represented as a rectangular prism, with a depth (z-direction) of $1.65 \mathrm{~m}$, and 

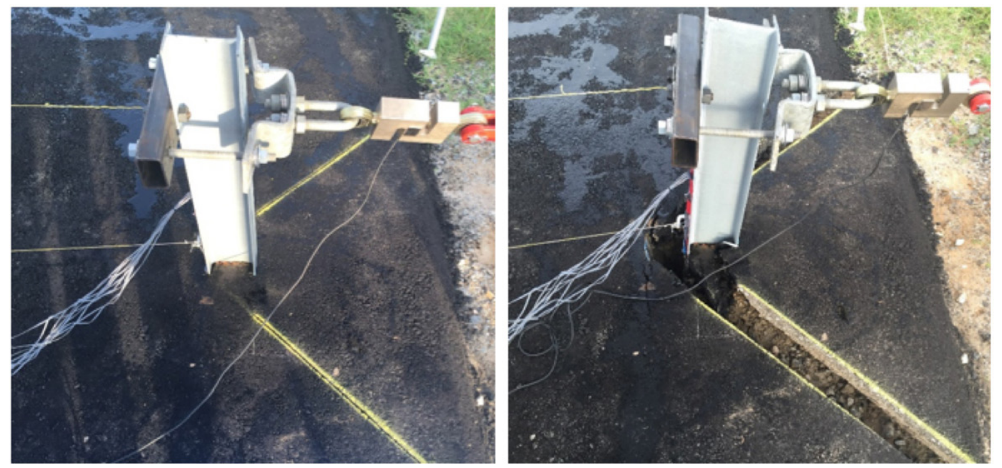

Figure 7: Diagonal pre-cut experiment.

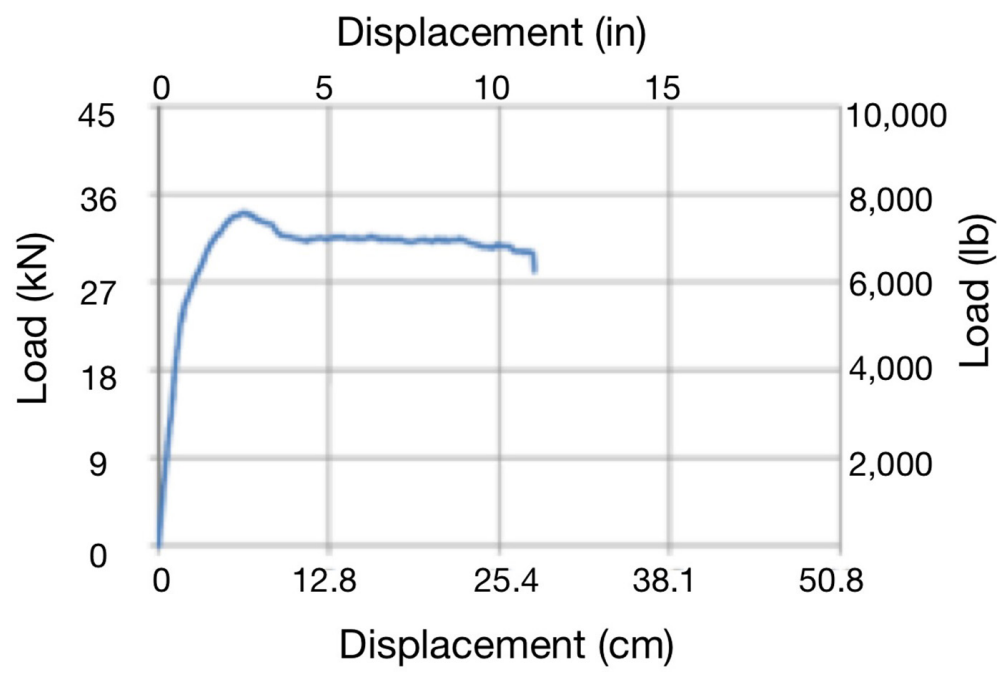

Figure 8: Load-displacement curve from diagonal pre-cut experiment.

planar dimensions of $9.75 \mathrm{~m}$ in the x-direction, perpendicular to the applied load, and $4.88 \mathrm{~m}$ in the y-direction, parallel to the applied load. The FEM is comprised of approximately 250,000 solid elements for the soil and asphalt and 1,000 shell elements for the steel post. Mesh sensitivity studies were conducted to ensure that the element sizes produced convergent results. The bottom boundary of the soil has fixed nodes, and the lateral soil boundaries are modeled using the non-reflecting boundary condition.

\subsection{Material models}

A piecewise linear plasticity constitutive material model was used for the steel post. The yield strength of the steel, modulus of elasticity, and Poisson's ratio were given as inputs using an experimental stress-strain curve. An experimental stress-strain curve for a typical guardrail steel post material was utilized to account for the strain hardening portion [19]. Shell element formulation number 16, fully integrated shell element, was selected because it does not exhibit hourglass modes. 
Material properties of the soil were obtained by experimental characterization of material specimens and calibration of the model with a reference experimental test on the system. Once the model was calibrated with a reference experimental test, the material properties were kept constant. The performance and accuracy of the model were then evaluated by comparing results from the model with further experimental tests. After this verification, the model can be used independently to conduct parametric studies. Different material models are available in LS-DYNA for modeling of soil; these material models were examined to find the most appropriate model to use for modeling of these components. After performing the simulations with the various relevant material models, the Mohr-Coulomb model [20] was employed to model the soil behavior.

To account for the viscous behavior of the asphalt, the shear modulus of the material was lowered to consider the viscous deformation effects under the quasi-static loading. The shear strength of the asphalt is also known to be pressure dependent. Mohr-Coulomb and Drucker-Prager material models are widely used to model asphalt. Because the Mohr-Coulomb constitutive parameters, friction angle and cohesion, are directly obtainable from laboratory tests, this material model was chosen to effectively model the shear strength of the asphalt. The density of the asphalt was estimated to be equal $2,300 \mathrm{~kg} / \mathrm{m}^{3}$ using laboratory tests. The Poisson's ratio and friction angle of the asphalt were specified as 0.35 and 35 degrees, respectively, which are typical values for asphalt $[21,22]$. The cohesion of the 118 day old asphalt at the temperature of $20^{\circ} \mathrm{C}$, using experimental unconfined compression tests on asphalt specimens, was estimated to be equal to $0.5 \mathrm{MPa}$. In addition, the $\mathrm{C}$ parameter for the soil was increased to $13 \mathrm{kPa}$ to account for the increase of soil strength due to asphalt compaction and moisture being trapped in the soil because of the asphalt cover.

The tensile rupture in the asphalt observed in the experimental tests was modeled using element erosion. A maximum principal stress criterion was initially used to remove the elements when the tensile failure criterion is met. However, the rupture in the asphalt was abrupt when this sole criterion was used, and the strength decreased dramatically, similar to what is commonly observed in very brittle materials. To account for the fact that asphalt is not as brittle as a rock (for example) and can accommodate larger strains before failing under tensile stress, a maximum principal strain failure criterion was added to the material model. Therefore, an element is removed when both the maximum principal stress criterion and the principle strain criterion are satisfied. By calibrating the post-peak response of the system, the maximum principal stress and maximum principal strain at failure were obtained as 0.6 MPa and 0.09, respectively.

\subsection{Experimental comparisons}

Comparisons between the two pre-cut experimental tests and the results of the LS-DYNA finite element model are shown in Fig. 9. The load-displacement curves generated by the finite element model are able to predict the peak force as well as the general displacement behavior of the post.

\section{INVESTIGATION OF FAILURE PLANE GEOMETRIES}

Using the validated finite element model, additional design patterns were investigated to find the most effective pre-cut pattern. Different possible pre-cutting alternatives that were considered are numbered and presented in Fig. 10. Based on the FEA results and analysis of peak forces and stresses in the post, designs number 2 and 3 were determined to be 

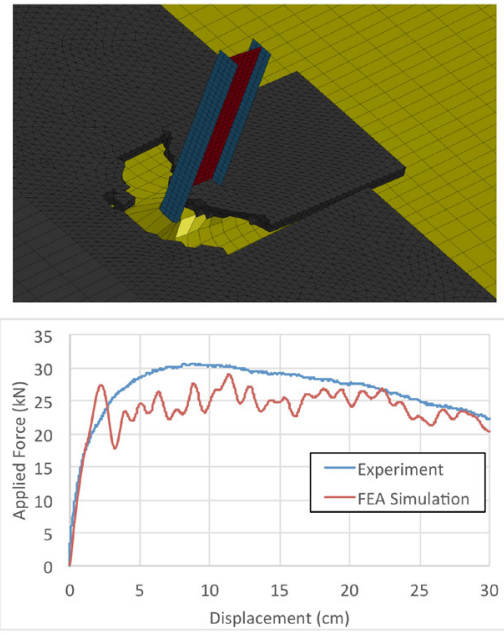

$5 \mathrm{~cm}$ Parallel Cut
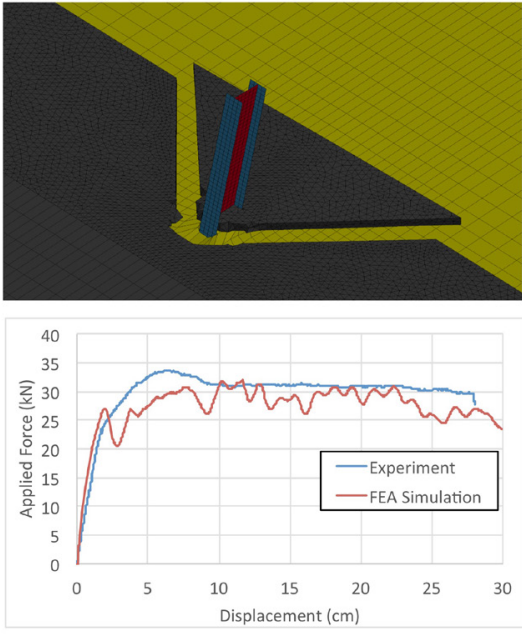

$9 \mathrm{~cm}$ Diagonal Cut

Figure 9: Comparisons between LS-DYNA FEM and experimental results.
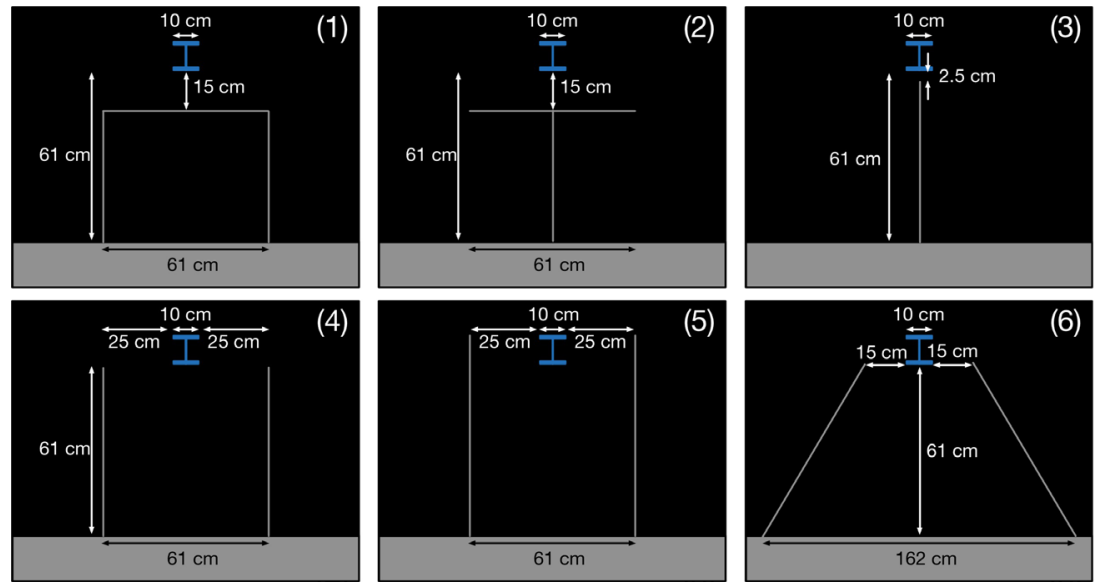

Figure 10: Pre-cut configurations considered.

ineffective, since they do not significantly decrease the asphalt ground restraint. In design number 3, the cut is applied in the asphalt layer where the asphalt is in tension. Because asphalt is not strong in tension, applying a cut in that area does not decrease the asphalt layer's strength significantly. Design number 2 has the same cut as design number 3 plus a horizontal cut behind the post. The horizontal cut closes on itself when a force is applied to the post and, therefore, it does not cause a decrease in the strength of the layer. From the finite element results, summarized in Table 1, designs 1, 4, 5, and 6 are effective designs, since they decrease the peak load and ground restraint significantly. These designs shorten the distance that the asphalt rupture needs to propagate until one part of the layer detaches from the rest of it. 
Table 1: Peak force summary for pre-cutting designs.

\begin{tabular}{lc}
\hline Design number & Peak force $(\mathbf{k N})$ \\
\hline 1 & 29.58 \\
2 & 35.63 \\
3 & 36.61 \\
4 & 28.20 \\
5 & 27.58 \\
6 & 28.02 \\
No pre-cut & 37.50 \\
\hline
\end{tabular}

\section{CONCLUSIONS}

An experimental and computational investigation was conducted to study the effectiveness of installing pre-cut fracture planes on asphalt performance. Specifically, the performance was evaluated in terms of ground restraint to develop configurations to be used in lieu of leaveouts. The results of the analysis showed that four of the proposed designs involving parallel and diagonal cuts were successful in reducing ground level restraint.

\section{REFERENCES}

[1] Georgia Department of Transportation, Standard Specifications: Section 641 - Guardrail.

[2] Georgia Department of Transportation, Construction Standards and Details: No.4381 and S-4.

[3] Scott, Static response of steel guardrail posts driven through asphalt vegetation barriers, 2015. Session 209, Transportation Research Board 94th Annual Meeting.

[4] Ray, M.H. \& McGinnis, RG., Guardrail and median barrier crashworthiness. Technical Report No. project 20-5, NCHRP synthesis 244, 1997.

[5] Reid, J., Ls-dyna simulation influence on roadside hardware. Transportation Research Record: Journal of the Transportation Research Board, 1890, pp. 34-31, 2004. http://dx.doi.org/10.3141/1890-04

[6] Atahan, A., Vehicle crash test simulation of roadside hardware using LS-DYNA: a literature review. International Journal Heavy Vehicle Systems, 17, pp. 52-75, 2010. http://dx.doi.org/10.1504/IJHVS.2010.029623

[7] Atahan, Finite element simulation of a strong-post w-beam guardrail system, simulation. Transactions of the Society for Modeling and Simulation, 78(10), pp. 587-599, 2002.

http://dx.doi.org/10.1177/0037549702078010001

[8] Borovinsek, M., Vesenjak, M., Ulbin, M. \& Ren, Z., Simulation of crash tests for high containment levels of road safety barriers. Engineering Failure Analysis, 14(8), pp. 1711-1718, 2007. http://dx.doi.org/10.1016/j.engfailanal.2006.11.068

[9] Ren, Z. \& Vesenjak, M., Computational and experimental crash analysis of the road safety barrier. Engineering Failure Analysis, 12(6), pp. 963-973, 2005.

http://dx.doi.org/10.1016/j.engfailanal.2006.11.068 
[10] Plaxico, C., Ray, M. \& Hiranmayee, K., Impact performance of the g4(1w) and g4(2w) guardrail systems: comparison under nchrp report 350 test 3-11 conditions. Transportation Research Record, 1720, pp. 7-18, 2000.

http://dx.doi.org/10.3141/1720-02

[11] LSTC, LS-DYNA keyword user's manual-vol. 1-v971 build R8.0.0. LSTC, 2015.

[12] Plaxico, C., Patzner, G. \& Ray, M., Finite element modeling and validation of a 3-strand cable guardrail systeminite element modeling of guardrail timber posts and the post-soil interaction. Transportation Research Record: Journal of the Transportation Research Board, 1647, pp. 139-146, 2007. http://dx.doi.org/10.3141/1647-17

[13] Wu, W. \& Thomson, R., A study of the soil-structure interaction behavior of highway guardrail posts study of the interaction between a guardrail post and soil during quasi-static and dynamic loading. International Journal of Impact Engineering, 34, pp. 883-898, 2007.

http://dx.doi.org/10.1016/j.ijimpeng.2006.04.004

[14] Tabiei, A. \& Wu, J., Roadmap for crashworthiness finite element simulation of roadside safety structures. Finite Element Analysis and Design, 34, pp. 145-157, 2000. http://dx.doi.org/10.1016/S0168-874X(99)00035-9

[15] Bligh, R.P., Seckinger, N.R, Abu-Odeh, A.Y., Roschke, P.N., Menges, W.L. \& Haug, R.R., Dynamic response of guardrail systems encased in pavement mow strips, fhwa/ tx-04/0-4162-2. Technical report, Texas Transportation Institute, 2004.

[16] Ross, H.E., Sicking, D.L., Zimmer, R.A. \& Michie, J.D., Recommended procedures for the safety performance evaluation of highway features. Technical Report NCHRP Report 350, National Cooperative Highway Research Program, 1993.

[17] Sicking, D., Mak, K., Rohde, J. \& Reid, J., Manual for Assessing Safety Hardware. AASHTO, 2009.

[18] Scott, D., White, D., Stewart, L., Bakhtiary, E. \& Lee, S.H., Evaluating the performance of guardrail posts installed by driving through asphalt layers. Technical Report 13-21, Georgia Tech, 2015.

[19] Bligh, R., Seckinger, N., Abu-Odeh, A., Roschke, P., Menges, W. \&Haug, R., Dynamic Response of Guardrail Systems Encased in Pavement Mow Strips. Technical report, Texas Transportation Institute, 2004.

[20] Coulomb, C., Essai sur une application des regles des maximis et min- imis a quelquels problemesde statique relatifs, a la architecture. Mem Acad Roy Div Sav, 7, pp. 343-387, 1776.

[21] Christensen, R. \& Bonaquist, D.W., Evaluation of indirect tensile test (idt) procedures for low-temperature performance of hot mix asphalt. Technical report, NCHRP, 2004. http://dx.doi.org/10.17226/13775

[22] Pellinen, TK., Song, J. \& Xiao, S., Characterization of hot mix asphalt with varying air voids content using triaxial shear strength test. 8th Conf. Asph. Pavements South Africa, 2004. 